ARI Research Note 87-64

Mf Re?

\title{
A Framework for a Theory of Mapping
}

Allan Collins and Mark Burstein

BBN Laboratories Inc.

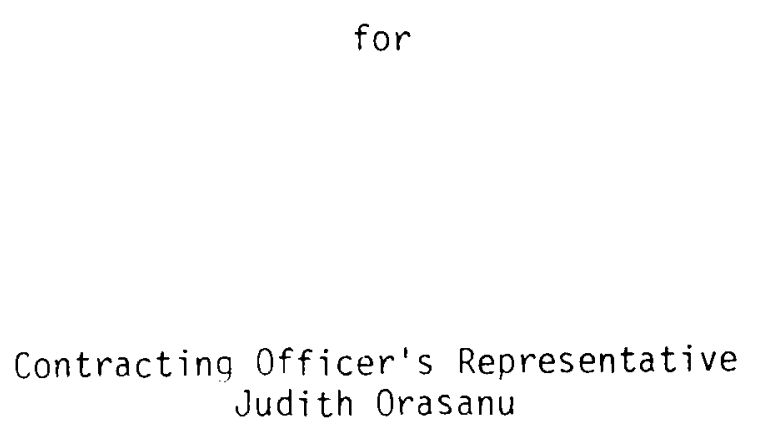

BASIC RESEARCH LABORATORY

Michael Kaplan, Director
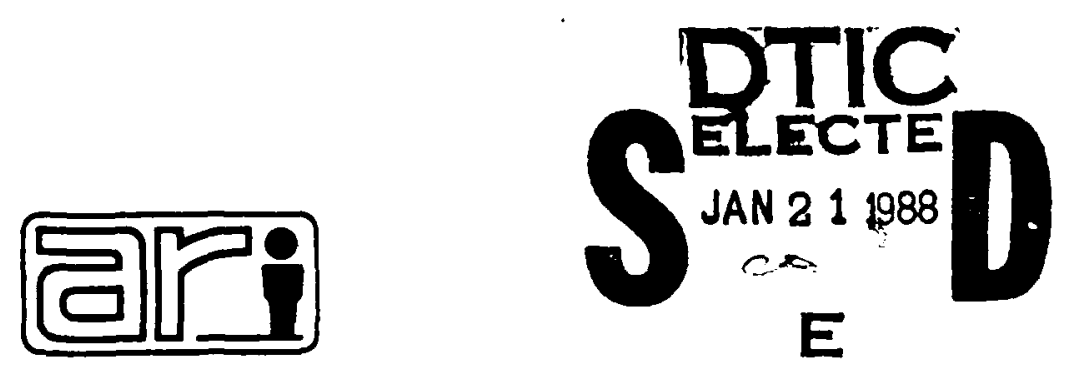

\section{U. S. Army}

Research Institute for the Behavioral and Social Sciences

December 1987

Approved for public release: distribution unlimited. 


\title{
U. S. ARMY RESEARCH INSTITUTE \\ FOR THE BEHAVIORAL AND SOCIAL SCIENCES
}

\author{
A Field Operating Agency under the Jurisdiction of the \\ Deputy Chief of Staff for Personnel
}

EDGAR M. JOHNSON

WM. DARRYL HENDERSON

Technical Dircetor

COL, IN

Commending

\author{
Research accomplished under contract \\ for the Department of the Army \\ BBN Laboratories, Inc. \\ Technical review by \\ Dan Ragland
}

\begin{tabular}{|l|}
\hline Accesslon For \\
NTIS GRALI \\
DTIC TAB \\
Unannounced \\
Just1flcation \\
\hline By \\
Distribution/ \\
\hline Avallability Codes \\
\hline Dist Avali and/or \\
Special \\
\hline-1
\end{tabular}

This epon. as womitted by the contrector, has been cleared Ic relesse 10 Defense Technical Intormalion Center IDTICl to comply with regulatory requirements. It has been giren no primery distribution othet than 10 DTIC and will be eveileble only through DTIC or other reference cervices wach as the National Technicel Intormation Service INTISI. The viem. Cpininns. onclor findings conteined in this repon ere those of ihe outhor(s) end should not be construes at en officisi Eeperiment of the Aimy position, policy. Or decision, unless so designaled by other officiel documentetion. 
UNCLASSIFIED

SECURITY CLASSIFICATION OF THIS PAGE (When Dere Entered)

\begin{tabular}{|c|c|}
\hline REPORT DOCUMENTATION PAGE & $\begin{array}{l}\text { READ INSTRUCTIONS } \\
\text { BEFORE COMPLETING FORM }\end{array}$ \\
\hline \begin{tabular}{l|l|l} 
1. REPORT NUMBER & 2. GOVT ACCESSION NO. \\
ARI Research Note $87-64$ &
\end{tabular} & 3. REGRIENT'S 9$\}^{T A L O G ~ N U M B R B}$ \\
\hline \multirow[t]{2}{*}{$\begin{array}{l}\text { 4. TITLE (and Subutia) } \\
\text { A Framework for a Theory of Mapping }\end{array}$} & $\begin{array}{l}\text { 5. TYPE OF REPORT A PERIOD COVEREO } \\
\text { Interim RepOrt } \\
\text { March } 86 \text { - March } 87\end{array}$ \\
\hline & 6. PERFORMING ORG. REPORT NUMBER \\
\hline $\begin{array}{l}\text { 7. AUTHOR(o) } \\
\text { Allan Collins and Mark Burstein }\end{array}$ & $\begin{array}{l}\text { 8. CONTRACT OR GRANT NUMBER(-) } \\
\text { MDA903-85-C-0411 }\end{array}$ \\
\hline $\begin{array}{l}\text { 9. PERFORMING ORGANIZATION NAME AND ADDRESS } \\
\text { BBN Laboratories InC. } \\
\text { Cambridqe MA } 02238\end{array}$ & $\begin{array}{l}\text { 10. PROGRAMELEMENT PROJECT, TASK } \\
\text { AREA WORK UNIT NUMBERS } \\
20161102 B 74 \mathrm{~F}\end{array}$ \\
\hline \multirow{2}{*}{$\begin{array}{l}\text { 11. CONTROLLING OFFICE NAME AND AODRESS } \\
\text { U.S. Army Research Institute for the Behavioral } \\
\text { and Social Sciences, } 5001 \text { Eisenhower Avenue, } \\
\text { Alexandria, VA } 22333-5600\end{array}$} & $\begin{array}{l}\text { 12. REPORT DATE } \\
\text { December } 1987\end{array}$ \\
\hline & $\begin{array}{l}\text { 13. NUMBER OF PAGES } \\
25\end{array}$ \\
\hline \multirow[t]{2}{*}{$\begin{array}{l}\text { 14. MONITORING AGENCY NAME A ADDRESS(It difforent from Controllind Oftico) } \\
\qquad- \text { - }\end{array}$} & $\begin{array}{l}\text { 15. SECURITY CLASS. (of thlo roport) } \\
\text { Unclassified }\end{array}$ \\
\hline & $\begin{array}{l}\text { 15a. DECLASSIFICATION/DOWNGRADING } \\
\text { SCHEDULE } n / a\end{array}$ \\
\hline
\end{tabular}

17. OISTRIBUTION STATEMENT (of the ebetract entered In Block 20, if difforent from Report)

18. SUPPLEMENTARY NOTES

Judith Orasanu, contracting officer's representative.

This matrial is to appear in S. Vosniadou and A. Ortony (eds.): Similarity and Analojical Reasoning.

19. KEY WORDS (Continue on eoveree elde II neceecery end ldently by block number)

Analogv and Similarity

Artificial Intelligence

Connitive Psycholony

Machine Learning

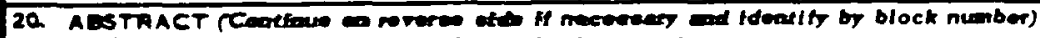

This research note is divided into three main sections. The first distinquishes the different kinds of information that are related bv analony and similarity mappings. The second section discusses the different contexts or tasks that qive rise to mappings. The third section catalogues different solutions proposed or possible for each issue. The note concludes by arquinn that the issue is not whether analogies are helpful or harmful, but what determines when they are heloful and when thev are harmful. 
1. INTRODUCTION

2. THUT IS MAPPED

3. CONTEXTS DN WHICH YAPPINGS OCCUR

3.1 TYPE OF TASK

3.2 NUMBER OF ENTITIES COMPARED

5. CONCLUSION 


\section{INTRODUCTION}

The literature on similarity, analogy, and metaphor ranges over many different kinds of mappings. Some of the disagreements arise because researchers are talking about different kinds of mappings or the different contexts in which mappings are made. Our goal is to clarify the issues being addressed and the critical distinctions that need to be made. We will attempt to consider the entire territory over which the discussion of mapping arises, but no doubt we will miss some of the critical distinctions and issues

We have divided the paper into three main sections. The first section distinguishes the different kinds of entities that are related by analogy and similarity mappings, and some of their more salient properties. The second section discusses the different contexts or tasks that give rise to mappings. The third section catalogues the set of issues we have identified in the literature, and identifies some of the different solutions proposed or possible for each issue. In a concluding section we briefly discuss the implications of this framework for research. 


\section{WHAT IS MAPPED}

The hypothesis we offer is that there are three fundamentally different kinds of entities that are mapped. systems, concepts, and properties and that all the other kinds of mappings discussed in the literature are variations on one of the three

System Mapping. The mapping from the solar system to the atom that Gentrer (Gentner, 1983) discusses is the classic example of a system mapping. In a system mapping it is critical to determine two types of mappings (Gentner, this volume)

1. Which components (i.e., concepts) in the source domain are mapped into which components in the target domain

2. Which properties of each component (including relations between components) in the source domain are mapped into which properties in the target domain

In the solar system/atom analogy, one furst has to decide what components map (sun - $\rightarrow$ nucleus, planets - $\rightarrow$ electrons) and then what properties map (planets orbit the sun $\rightarrow$ electrons orbit the nucleus)

Concept mapping To answer the question (Collins. 1978) "Was Nixon a crook" or to decide how likely Linda is to be a feminist bank teller (Tversky and Kahneman. 1980. Smith \& Osherson. this volume) requires only a mapping across the properties of two concepts. There is no decomposition into components, as there is with a system mapping So. in the case of Linda in Smith and Osherson's (this volume) account, you consider the properties of salary, education, and politics in the mapping process. comparing Linda and feminist bank tellers with respect to these properties

Property mapping. The simplest kind of mapping specifies a particular property of two concepts for comparison, as when one judges whether an object 3 inches in diameter is more similar to a quarter or a pizza (Rips. this volume). (This example is actually a double mapping, discussed later under three-element comparisons, between a 3 inch object and a quarter. and between a 3 inch object and a pizza - system and concept mappings can also involve double mappings) Property mappings differ from concept mappings in that the concepts are compared with respect to a particular property rather than with respect to many properties 
The critical distinction between these three kinds of mappings is that the system mappings involve component (or object) mappings as well as property mappings, that concept mappings involve multiple property mapping., and that property mappings involve individual properties of two concepts. The distinction between system and concept mappings is not entirely straightforward. For example, one elementary text we studied (Collins. Gentner, and Rubin, 1981) explained the composition of the earth by analogy to a peach. There is the crust which is analogous to the skin, the mantle analogous to the fruit, and the core analogous to the pit. This may appear to be a concept mapping, since it is a comparison of the properties of two concepts. But in fact it is a system mapping. since it requires first decomposing the earth and peach into their components (2.e., the three layers), and then comparing the properties of each pair of components (e.g., the skin and crust are both very thin), and their relations to each other. Thus the distinction between a system mapping and a concept mapping rests upon whether there is a two-stage process of first mapping an organized set of components and then the properties of each component ( 1 e, a system mapping) or a single-stage process of mapping properties (ie, a concept mapping)

To give a second example of a system mapping that may be difficult to recognize. one might hypothesize (Collins and Michalsk1, 1987) that a bird's pitch depends on the length of the birds neck. which is why ducks quack and geese honk, and more generally why small birds sing and big birds squawk (Malt and Smith, 1984) This hypothesis might be generated by analogy to the fact that human pitch (e.g. children vs adult volces) depends on the length of the windpipe. To make the inference about birds by analogy to humans requires mapping windpipe length onto neck length. and human pitch onto bird pitch. Because the analogy involves both a mapping between their components (e.g windpipes and neck) and a mapping of some of their components properties (relative length). it is a system mapping. In this case the property mapped (e.g. "pitch is inversely related to length") is a relational property in Gentner's (this volume) terms or a mutual dependency in Collins and Michalshis (Collins and Michalski, 1987) terms.

There are a number of other kinds of mappings discussed in the literature whict. we think are special cases of these three kinds of mappings. We will briefly describe each 
Procedure mapping VanLehn and Brown (VanLehn end Brown, 1980) discuss mapping between the addition and subtraction procedures we learn in school and different addition and subtraction procedures with Dienes blocks (which are wooden blocks in three denominations. units are small squares, tens are ten unit blocks long. and hundreds are ten by ten unit blocks). Similarly. Anderson and Thompson (this volume) describes mapping between the procedure for factorial and that for summorial Mappings of procedures are essentially system mappings, where the components of the procedure must first be mapped (e.g. unit blocks onto the numbers in the right hand column, etc.), and the manipulations on those components are subsequently mapped like properties

Problem mapping. Ross (this volume), Holyoak \& Thagard (this volume), and Carbonell (Carbonell, 1986), among others, discuss mapping between a problem you are trying to solve and an earlier problem you have solved. This kind of mapping is frequently used in science texts where students solve new problems by referring back to the sample problems worked in the text. Gick and Holyoak (Gick and Holyoak. 1980 , 1983; Holyoak and Thagard, this volume) discuss the analogy between a fortress problem, where an army must split up in small units to capture a fortress, and Duncker's (Duncker, 1945) ray problem, where a ray source must be split in order to kill a tumor without destroying healthy tissued around it. Problem mappings require mapping of components first (e.g. ray - $>$ army units, tumor - $>$ fortress), and so they are system mappings

Story Mappings Gentner and Landers (Gentner and Landers, 1985) and Ross (this volume) have studied mappings between stories. These again are simply system mappings. where it is necessary first to map the characters or objects from one story to the other and then the relations or events between these entuties

There are undoubtedly other kinds of mappings that are made. but we think they will all be variations of the three kinds of mappings we have identified 


\section{CONTEXTS IN WHICH MAPPINGS OCCUR}

Various tasks or real world demands require different kinds of reasoning when relating entities Our taxonomy of contexts in which mappings occur consists of two dimensions. type of task and number of entities compared. The overall structure of the taxonomy of contexts is shown in Table 1.

These two dimensions, type of task and number of elements, define a space of possible contexts in which mappings are made. There may be some cells empty in the space, but most combinations are possible

\subsection{TYPE OF TASK}

Type of task breaks down into three basic categories. comparative judgements. mappings, and conceptual combinations. We will briefly describe six different kinds of comparative judgements, and then two kinds of mappings. Last. we will briefly discuss conceptual combination. The comparative-judgment types are derived primarily from the Rips (this volume) and Linda Smith (this volume) papers. This may not be a complete list of comparison judgements, but it covers the types discussed in this volume

\section{A. Comparative Judgements}

1. Similarity judgement. Judging how similar two entities are is a common task in psychological experiments (Tversky, 1977, Rips, this volume. Smith \& Osherson, this volume, Barsalou, this volume). Smith and osherson (this volume) and Collins and Michalskı (Colluns and Michalski, 198T) argue that similarity judgments affects the certainty of many inferences people make. Similarity judgments obviously can apply to pairs of systems, concepts, or properties

2. Typicality judgments. Typicality has been studied in psychology since Rosch (Rosch, 1975), and plays much the same kind of role in plausible reasoning as similarity (Collins and Michalski. 1987). Rips (this volume) has shown convincingly that typicality and similarity judgment are not always made in the same way. so they must be distinguished in any theory Like similarity. typicality applies to pairs of systems, concepts, or properties

3 Categorization judgments Rips (this volume) discusses the similarity theory 
of categorization, which he rejects. In any case, categorization requires a comparison between properties of two entities, the thing to be categorized and the category. Categorization only applies to systems and concepts, not to single properties of concepts. except when they are treated as concepts in their own right

4 Identity judgments. Linda Smith (this volume) raises the issue of making identity judgments between entities - that is comparing whether all their properties are the same. Of course, no two entities are ever exactly the same (e g. her examples of identical elements are not quite the same darkness or shape). so it is necessary to learn what degree of variability of a property can be called the same. Identity judgements therefore depend on context.

5. Overlap judgments. None of the papers in this volume mention overlap judgments (e.g. whether therapists are psychiatrists), but logically if one includes categorization and identity judgments, then overlap and difference judgments must also be included. Evaluating a "some" statement (e g. "Some women are doctors") requires making an overlap judgment (Meyer, 1970).

6. Difference judgments The question of whether two entities are different (e.g. "Are whales fish?") also involves a comparison of properties. Like categorization, identity, and overlap judgments, difference judgments are contextually defined For example, whales and fish are different, but both are animuls and can be treated as the same in some contexts, such as grouping things as plants and animals.

The last four of these judgments categorization. identity, overlap, and difference correspond to the four possible relations between two curcles in Venn diagrams, as shown in Figure 1.

\section{B. Mappings}

The other type of task that is referred to frequently in the literature is one of mapping properties, components, or both from the source domain to the target domain

Property mapping. Most of the work on analogy (e.g. Anderson \& Thompson. this volume. Gentner, this volume. Holyoak \& Thagard, this volume) concerns itself with bringing properties (including relational properties) of objects in the source doman over into the target domain. A similarity or typicality judgment between the source and target is made before mapping a property over, and affects the certanty with which the property is believed to hold for the target domain for example, before deciding that the pitch of birds depends on their neck length, based on an analogy to the human vocal tract, a person would compare humans and birds with respect to 
their similarity, particularly on those properties related to sound prcduction tin this case, properties of the relevant components, such as vocal cords and nectisl A person's certanty abcut whether the property holds for birds depends on this similarity judgment

Component mapping Sometimes in the mapping of two systems, whole components are introduced by the mapping In the earth/peach analogy, the text introduced two new components of the earth to students (the mantle and the core) in the course of explaining the analogy. This same thing can occur when people consider an analogy in their own mind (Collins and Gentner, 1980). For example, in relating the texture of foods to materials science, one might notice that chewiness corresponds roughly to elasticity, crispness to ductulsty, and then wonder what jusciness corresponds to one possibilty is hquid-filled porosity, a critical concept in geology:

\section{Conceptual Combinations}

Smith and Osherson (this volume) rasse the possibility that conceptual combination (feminist + bank teller - -> feminist bank teller) is another task that a theory of mapping should address we see conceptual combination, as they have modeled 1t, as primarily addressing the issue of how property mappings are combined when there is prior information about the properties involved in the target system This becomes particularly important when learning or making predictions from multiple enalogies, and in interpreting descriptive metaphors

\subsection{NUMBER OF ENTITIES COMPARED}

Number of entuties compared is the other dimension we have identified with respect to the contexts in which analogies occur. This can range from two. as in the earth/peach mapping, to four as in analogles like wolf dog tiger cat, and the geometric analogies considered by Evans (Evans, 1968). Slightly different constraints operate in two. three. and four-element mappings, shown in Figure 2

Two-element comparisons. Many of the mappings discussed in the hiterature leg Gentner's (this volume) water flow to heat flow mapping. and Holyoak \& Thagards (this volumel fortress problem to ray problemi are two-element mappings in a two-element 
mapping there is a source from which properties or components are mapped onto a target. There are no other concepts, even implicitly. that are compared in a twoelement comparison.

Three-element comparisons A good example of a three-element mapping is the task used by Rips (this volume) where subjects had to decide whether a three inch object was more likely to be a pizza or a quarter. In many tasks tinat appear to be two-element mappings, there may be a comparison element implicit that subjects generate on their own in doing the mapping. For example, if you tell a child that a whale is a mammal. they may compare whether whales are more like mammals or fish. which is a three-element comparison. Three-element comparisons, therefore, compare properties of $X$ to those of $Y$ vs. $Z$.

Four-element comparisons. Standard analogy tests pose questions using the syntactic form W.X.Y.Z. We view such problems as falling into two categories, based on whether the analogy's interpretation depends on one or two ccmparisons. True fourelement comparisons depend on both sets of comparisons, as in the analogy wolf dog tigercat. The within-group comparisons (e.g. wolf dog and tigercat) determine the properties or dimensions along which the pairs differ (wildness or not). and the between group comparisons identify the dimensions along which the pairs are similar (feline or canine class membership). Evans (Evans, 1968) discusses the need for both kinds of comparisons (relating the components of both $W$ and $X$ and $W$ and $Y$ ) in solving some geometric analogies.

Some analogies stated in the same syntactic fashion are more properly interpreted as analogies between two systems, where $W$ and $X$ are related in one system, while $Y$ and $Z$ are related in an analogous system. For example. Johnson-Laird (this volume) discusses, the analogy water.Sluce.Gas.Jet Here, there is a betweensystem mapping of water - $>$ gas and slusce - > jet. but comparison of water and sluice. or gas and jet is not useful. Instead, there are relational systems relating each pair (e g, a sluice directs water and a jet directs gas) True four-element mappings relate each concept in two different mappings, but in Johnson-Lairds example, a similarity judgment is required between the functional relations in the iwo systems 


\section{ISSUES FOR A THEORY OF MAPPING}

There are a number of issues running through the papers in this volume and the literature more generally. In part they reflect the set of subprocesses outlined by Gentner (this volume), but they have wider scope our attempt here is simply to delineate the set of issues as best we can, and to discuss possible resolutions to them. We start with the most microscopic issues and work up to the more macroscopic issues.

How are individual properties compared?

Potentially there are two kinds of properties that a theory must take into account. discrete properties (e g. male or female) and continuous properties (e g size). Tversky and Gatı (Tversky and Gatı. 1982) have shown how it is possible to treat all continuous properties as if they were discrete. Another possibility is to treat all discrete properties as continuous (a person is on a continuum of male/female and most people fall near one or the other ends of the continuum).

Rips (this volume) addresses the question of how continuous properties are compared for different kinds of three-element comparisons. similarity. typicality, and categorization judgments, which he finds are judged differently. His results suggest that categorization judgments are based on the relative height of the distribution e.g a three inch object is more likely a pizza than a quarter, because the distribution of pizzas is higher at that point. His results for similarity judgments suggest both height of the distribution and distance from the mean (or mode) come into play. Typicelity judgments appear to fall in between categorization and similarity. as if some subjects treat them like categorization judgments and others like similarity judgments (or perhaps they are combination judgments)

There are many possible functions for computing any of these judgments for example, similarity might be based on the relative distance between modes of the distribution compered, typicality judgments might be simply similarity judgments between a concept and its superconcept, as Smith \& Osherson (this volume) assume Rumelhart's (this volume) theory probably makes a prediction as to which of these functions will best fit the data, but he is not explicit on this point Most of the other theories take no stand on this issue. 
How are judgments from different properties combined?

Tversky (Tversky. 197T) proposes a combining function for similarity judgments. which Smith and Osherson (this volume) have adopted for their theory of decision making The essence of the Tversky combination rule is that matching properties increase similarity and mismatching properties decrease similarity between concepts Mismatching properties consist of two sets property values of one concept that the other does not share, and property values of the other that the first does not share Mismatching properties include properties where one concept has a known value and the other has no known value Each of these three sets (one matching and two mismatching properties) is weighted appropriately depending on the direction of the judgment Thus people think North Korea is more like China than China is like North korea, because there are many properties they know about China that do not apply to North korea. but few properties they know about North korea that do not apply to China (Tversky. 1977)

The Tversky rule is defined only over similarity judgments and discrete properties. If one adopts the view that all properties are continuous, then a modification of the Tversky rule is necessary. Whether it applies to other kinds of judgments (e.g categorization judgments) is an open question And of course, there are an infinite number of other combination rules, some of which might still be viable given Tversky's (Tversky. 1977) data

How do people access similar entities?

The question of access is fairly central to the papers of Ross. Gentner. Bransford et al. Barsalou, Brown and kane, and holyoak and Thagard (this volume) It is called "noticing" by Ross. All of these papers address the access issue for the case where the source must be found in memory. As Johnson-Laird (this volume) point out, the source is often given, as when a text explains that the earth is like a peach or the atom like a solar system In Ross's paradigm, when one is working problems, a person may go back through a book to find a similar problem This access may or may not be governed by the same properties as the access from memory

Gentner (this volume) proposes that attributes (or superficial properties) govern access more than relational properties This seems to accord fairly well with both her 
data and those of Gick and Holyoak (Gick and Holyoak, 1983) Rumelhart ithis volumel takes the position that access is governed by a : ich on all microfeatures. but in different contexts it may be attributes that match or higher-order relational features These positions are compatible if one posits that superficial attributes are the most avalable, and therefore will usually domate higher-order relations in most matches

There is some evidence leg. (Chi. Feltovich and Glaser. 1981)) that part of becoming an expert is learning to pay attention to higher-order relations rather than superficial attributes This also accords with Ross's (this volume) observation that superficial properties will mislead people if the principles underlying the problem (ie higher-order relations) are confusable Brown and hane (this volume) give evidence that functional fixedness and cognituve embeddedness of problem solving contexts are sources of diminished accessability to potential analogs in children, as well

How is knowledge about the source reconstructed?

Ross (this volume) points out that people often have to reconstruct their knowledge about the source domain after they have accessed an analogy This reconstruction process is guided by the knowledge being sought about the target doman. For example, if people are told that heat flow is like water flow (Gentner. this volume) since they do not have a particularly good understanding of water flow (Gentner and Gentiner. 1983), they must in part figure out what they know about water flow that it flows from one contaner to another as long as there is a difference in the height of the water in the two containers, that the surface area of the water in the contaner does not matter, that the flow rate is proportional to the diameter of the connection between the containers, etc. Which properties of the source domain people think of depends on what aspects of the target they are trying to understand. as Ross (this volume) has found in his studies

What governs which properties are transferred?

This is the central argument anmating most of the discussion in the analogy literature. We will briefly delineate the different positions

Ortony (Ortony. 1979) advocates the position that salience imbalance governs transfer that is. those properties are transferred that are important in the source domain but not important in the target domain. For example. Sam is a hippopotamus transfers fatness. since that is a typical property of hippos, but not of people 
Gentner (Gentner, 1983) proposes a syntactic theory that states that. in analogies, relational properties are transferred but attributes (1.e non-relational properties) are left behind. Furthermore, according to her systematicity principle. relational properties that are a part of a system of relations (e.g. the large mass of the sun attracts the planets into orbiting around it) are more likely to be mapped across

Holyoak and Thagard (this volume), Johnson-Laird (this volume), Carbonell (Carbonell, 1986), and Burstein (Burstein, 1986), while there are differences in their views, take a position on mapping that appears somewhat different from Gentner Their position is that a system (or schema) of properties is mapped over, as Gentner proposes, but with two differences. (1) attributes will be mapped if they are part of the system, and (2) the major problem is to decide which system to map over. For example, if the analogy was made between the solar system and a person tanning themself under a sun lamp. the properties mapped would have to do with the heat being transmitted, the person rotating to cover all sides, the yellow color of the lamp. etc

It turns out that the latter criticism may be handled by the structure mapping engine (Falkenhainer et al. 1986. Gentner, this volume) that was built recently to embody the Gentner theory. This system compares repesentations of two domains to decide which relations fit into a connected system that can be mapped into the target domain. Because it is effectively comparing all possible sets of relations between the objects considered, it is to some degree automatically chosing a "best system" to map However, some pragmatic, contextual selection mechanisms will almost certainly be required as well. This is particularly true during learning, when people usually do not know enough about the target domain to pick out corresponding systems simply by matching (Burstein. 1986).

An important test of any of these computer models (Burstein. 1986. Carbonell. 1986. Gentner, this volume. Holyoak and Thagerd. this volume) is whether they can select two different mappings from a source domain (e.g. the solar system) depending on what aspects of the source domain are relevant to the target domain (e $g$ the atom vs a person tanning). None of the models has, as yet addressed this central problem directly 
Whether goals and subgoals guide the selection of the system to be mapped often arises in the debate between these two positions But that is probably because the latter researchers are all working with analogies in problem solving, whereas Gentner is dealing mainly with explanatory analogies. Certanly both sides would agree that goals are critical properties to map in problem-solving analogies and play the same central role that causal relations play in explanatory analogies

Anderson and Thompson (this volume) rely on a set of three principles (1e. "no function is content", "sufficiency of functional specification", and "maximal functional elaboration") to determine what is mapped. Although it is not clear to us exactly how these principles operate, they indicate the use of function as the man criteria for selecting what to map, and so would seem to fall into the latter camp.

In our view the positions of Gentner on the one hand and that of Holyoak and Thagard. Johnson-Laird. Carbonell, and Burstein on the other hand are not that far apart given the centrality of systems of properties or schemas that are mapped over The Ortony theory is orthogonal to that issue, and could operate in conjunction with some kind of system mapping. Whether the Anderson and Thompson position is genuinely distinct, or reduces to the use of system properties as well, remains to be seen.

How are multiple mappings merged together?

This issue is raised by Burstein (Burstein, 1985, 1986, 1987). Spiro (this volume) and Collins and Gentner (Collins and Gentner, 1983). In Burstein's work, students were learning to program and were forced to combine the mappings of systems like puttings things in boxes and the the interpretation of arithmetic equalities in forming a mental model to understand computer statements like $A=B+1$. Collans and Gentner (Collins and Gentner. 1983, 1987) describe how subjects combined different analogies (e $g$ billiard-ball analogy, a rocketship analogy, a crowded-room analogy) in understanding evaporation processes. It is clear that people frequently construct their understandings of systems by multiple mappings, and so theories will have to specify how conflicts are resolved about what properties to map from each analog. and whether, in fact. some form of conceptual combination is required to merge related properties mepped from several different sources In Bursteins model conflicts between mappings are usually resolved by reasoning from specific examples in 
the target domain that cause one or another analogical mapping to fall However. the hypotheses that are eventually selected must still be integrated with what had been mapped previously or was otherwise known about the target domain (Burstein. 198i)

Burstein (Burstein. 1985) and Collins and Gentner (Collins and Gentner. 1983) also reise the issue of vertical integration of mental models Analogies do not always map onto the same level of description of a target system. In such cases, one cannot directly merge analogs Instead. the mapped structures must be maintaned distinctly, and rules of correspondence formed between the different views or levels of abstraction described by the different analogical models.

How are mappings refined?

After a mapping is made, some properties carried over into the target domain will not apply. How are the correct properties identified and replaced? Both Burstein (Burstein. 1986) and Anderson and Thompson (this volume) address this question in the context of mapping computer program statements. In Bursteins model. analogically mapped predictions are compared to the actual results in target domain examples if the predictions are wrong. alternative structures are considered for mapping, either from the same or a different source domain. Anderson and Thompson discuss several examples of fallures due to overgeneralization from an analogy, and suggest that they may be handled by searching for contextual features that were not mapped. and adding them as preconditions.

Another kind of refinement occurs when successful analogies are extended to encompass new sets of corresponding systems or related causal principles in addition to mapping new relational properties. this kind of analogical extension can lead to the introduction of new object or concept correspondences. For example, in the kinds of demonstration physics experiments that are often used to explain the diffraction and interference behavior of sound and light by using water wave tanks. a number of experimental objects are introduced to cause different wave behaviors Each object that is introduced in these experiments must be related to an analogous object that causes a similar kind of interference with light or sound In this sense, each new experiment described causes the refinement of the analogy between water waves and light or sound waves, because new objects and new causal implications are placed in parallel 
What is generalized from a mapping?

This is the question of how. when. and if generaizations are made based on a mapping between two domains for example. one hypothesis might be that the corresponding components in the two systems are replaced by their common supersets and the generalization is stored as a set of (possibly generalized) relations on these common supersets. Both Gentner (this volume). Anderson and Thompson (this volume) and Winston (Winston, 1982) have addressed this issue to some degree. although no specific claims have been made

It is not at all clear that analogies aiways lead to new generalizations Most analogies are only useful because they map one or two specific pieces of information from one domain to another In such cases, the generation of a new $r$ neral principle may not be warranted

At the other extr ine. attempting to generalize from an analogy that related radically different classes of objects by a new principle calls for a strong form of conceptual reclassification, as when sound and light are reclassified as waves lery strong evidence of the analogy's pervasiveness may be needed for this kind of reclassification to occur Alternatively. "bridging analogies" can be used to show why the analogy is justified Clement (Clement, 1981, 1986) gives examples of series of bridging analogies designed to convince people of the generality of phyiscal laws One set of these analogies shows how the behavior of a spring is related to the longitudinal and torsional flex of a wire, by considering intermediate cases where the wire is partially bent Clement (Clement, 1986) also discusses Newtons analogy between the moon and an apple falling from a tree. with the a sequence of bridging analogs where a cannonball is fired at greater and greater speeds until it is in orbit around the earth

How does the process of mapping develop?

This is the central issue raised by Linda Smith's paper (this volume) In it. she proposes that development proceeds from overall resemblance matches to identity matches and finally to dimensional matches Her proposal perhaps is best summed up by saying that children learn to make finer discriminations in their comparison processing with age 
Her thesis rases the question of how children can make overall resemblance comparisons without being able to make individual property comparisons This is not really a paradox from the vantage point of the kind of microfeature theory proposed by Rumelhart (this volume) Overall resemblance comparison in Rumelharts theory can be carried out by comparing two concepts with respect to all their microfeatures This requires no identification of microfeatures with particular properties (like color) of entities in the world Based on the kind of perceptual learning described by Bransford and his colleagues (this volumel. dimensions or subgroups of the microfeatures will emerge as contrastive sets of microfeatures that inhibit each other Making an identity match would seem to require learning how much variability is possible on any dimension so that one can assess whether the difference between two entities falls below the normal range of variability on that dimension. In any case, the papers of Smith. Rumelhart. and Bransford et ai together promote a consistent picture of how similarity matching develops

Are analogies helpful for learning?

This issue was raised by Halasz and Moran (Halasz and Moran. 1982). Their position is that if you give people explanatory analogies, such as the analogy that computer addresses are hke boxes (Burstein. 1986) or that heat flow is like liquid flow Gentner. this volumel, you lead them to make more wrong mappings than helpful ones So they argue that it is better to give people descriptions of the mechanisms involved. rather than analogies

There are at least two arguments aganst the Halasz and Moran (Halasz and Moran. 1982) position. First, when people learn about novel systems, they are going to impute mechanisms to them. In order to understand any mechanistic description. they have to draw from their stock of basic mechanisms, such as Carbonell (this volume) or Collins and Gentner (Collins and Gentner. 1983) have described. So, whether you give students an analogy or not, they are going to make an analogy to some mechanism they already understand. The continuum from remembering, to reminding, to analogy that Rumelhart (this volume) describes is operating here Subjects will pull in the mechanism they know about that matches most closely By giving students an explicit analogy, you then accomplish two things (a) you make sure they impute the best matching mechanism. and (b) you know what wrong inferences they are likely to draw so that you can try to counter them as you explain the mechanism 
A second argument aganst the Halasz and Moran (Halasz and Moran 1982) position is that the power of analogies for teaching derives from the fact that they provide a well-integrated structure that can be assimilated all at once This structure may have acquired over a long period of time, as Vosniadou (this volume) shows for the solar system. So by telling someone the atom is like a solar system. the have a well-integrated structure acquired over many years that they can map as a whole in order to understand the atom. Thus they do not have to recapitulate the same long learning process for the atom. Analogies are particularly powerful where there is a competing structure already in place that the teacher is trying to dislodge

The Halasz and Moran (Halasz and Moran, 198?) position. however, has to be correct if the analogy introduces too many wrong mappings. Therefore, we would argue that the issue is not whether analogies are helpful or harmful, but what determines when they are helpful vs. when they are harmful for learning 


\section{CONCLUSION}

Most researchers are working in a little corner of this framework. which is fine One use of the framework is to help them see what the rest of tine territory looks like in order to help them extend their theory to cover the whole territory By tryng to extend their theory in this way. it puts additional constraints on theory construction. which will help researchers refine their theories. Furthermore, as theorles are extended to cover the whole domain. they will bump up against other theories in more ways which will lead to fruitful controversies and issues to be settled empirically Psychology and artificial intelligence have a tendency to construct task-based theories and need to enforce on their theorists the desirability of constructung more global theorles 
Table 1

Contexts in which mappings occur

I. Type of Task

1 Comparative judgments

a. Similarity judgments

b. Typicality Judgements

c. Categorization judgments

d. Identity judgments

e Overlap judgments

f. Difference judgments

2. Mappings
a. Property mappings
b. Component mappings

3. Conceptual combinations

II. Number of Entities Compared

1. Two-element mappings

2. Three-element mappings

3. Four-element mappings 


\section{References}

Burstein. Mark $\mathrm{H}$ Learning by Reasoning from Multiple Anaicgies Datoral dissertation. Yale University, 1985

Burstein. Mark $H$ Concept Formation by Incremental Analogical Feasonirg and Debugging in Michalski, $R S$. Carbonell, $J$ G and Mitchell. $T$ M IEd Marizie Learning bolume $I I$ Los Altos. CA Morgan Kaufmann Publishers. ine isE0 Also appeared in the Proceedings of the Second International Machine Learning Horkshop, Champaign-Urbana, IL. 1983

Burstein. Mark $H$ Incremental Learning from Multiple Analogies In Froceedings of Analogica-85 Boston. MA Pitman, 1987 Forthcoming

Carbonell. Jame G. Derivational Analogy. A Theory of Reconstructuve Problem Solving and Expertise Acquisition. In Michalski, $R \quad S$. Carbonell $J$ G and Mitchell. T M (Ed). Machine Learning Volume $l l$ Los Altos. CA Morgan Fiafman Publishers. Inc., 1986

Ch. M. Feltovich, P., and Glaser, R Categorization and representation of physics problems by experts and novices Cognatie Science. 1981, 5(2) 12:-152

Clement. J Analogy generation in scientific problem solving In Proctedings of the Third Annual Conference of the Cognitize Science Society Berbeley. CA Unversity of California, 1981

Clement. J Methods for evaluating the valudity of hypothesized analogies in Proceedings of the Eighth Annual Conference of the Cognutize Scrence Society Amherst. MA University of Massachusetts. 1986

Collins. Allan Fragments of a Theory of Human Plausible Reasoning in $D$ L Waltz (Ed). Theoretical lssues in Natural Language Processing Lrbana-Champaign. IL Cniversity of Iminois, 1978

Colluns. Allan and Gentner. Dedre. A Framework for a Cognitue Theory of Winting in $L W$ Gregg and $E$ Steinberg (Eds). Cognitive processes in uriting. An interdisciplinary approach. Hillsdale. NJ Erlbaum. 1980

Collins. Allan and Gentner. Dedre Multiple Models of Evaporation Processes in Proceedings of the Fifth Annual Conference of the Cognitue Scrence Society Rochester. Ni. Cognitive Science Society. 1983

Collins, Allan and Gentner. Dedre How People Construct Mental Models in $x$ Qumn and D Holland (Eds). Cultural Models in Thought and Language Cambridge. L'F: Cambridge Linversity Press, 1987 In press

Collins, A and Michalski. $R$ The Logic of Plausible Reasoning A Core Thecry Submitted to Cognitrve Science.

Collins. A. Gentner, D and Rubin, A. Teaching Study Strategies (Tech Rep Report No 4794) Bolt Beranek and Newman Inc. 1981

Duncker. r: On problem solving Phychological Monographs. 1945. Vol 581270) 
Evans, Thomas G A Program for the Solution of Geometric Analogy intelligence Tes: Questions. In Marvin L Minsky (Ed). Semantic Information Processing Cambridge. Massachusetts M.I T Press, 1968

Falkenhainer. B. Forbus. $K$ and Gentner $D$ The Structire-Mapping Engine In Proceedings of AAAl-86. Los Altos, CA. Morgan Kaufman, 1986

Gentner. Dedre. Structure-Mapping. A theoretical framework for analogy Cognatize Science, 1983, $7(2), 155-170$.

Gentner, $D$ and Gentner, D. R. Flowing waters or teeming crowds Mental models of electricity. In Gentner, D and Stevens. A L. (Eds.), Mental Models Hillsdale. New Jersy. Lawrence Erlbaum Associates. 1983

Gentner, $D$. and Landers, $R$ Analogical reminding A good match is herd to find In Proceedings of the International Conference on Systems. Man and Cybernctics Tucson. AZ. Unversity of Arizona. 1985

Gick Analogical problem solving. Cognative Psychology, 1980(12). pp 306-355

Gick. Schema induction and analogical transfer Cognitive Psychology. 1983115). pp $1-38$

Halasz. Frank and Moran. Thomas $P$ Analogy Considered Harmful. In Proceedings of the Human Factors in Computer Systems Conference Gathersburg. MD , 1982

Malt. Barbara C. and Smith. Edward E. Correlated properties in ratural categories Journal of Verbal Learning and Verbal Behavior, 1984, 23 250-269

Meyer. David $E$. On the representation and retrieval of stored semantic information Cognitize Psychology. 1970, 1, 242-300

Ortony, Andrew Beyond hteral similarity. Psychological Revieu, 1979. 8\%, 161-180

Rosch. E. Cognitive representations of semantic categories. Journal of Experimental Psychology. General, 1975. 104. 192-233.

Tversky, A. Features of similarity. Psychological Review. 1977, 84, 327-352

Tversky, A and Gati, I Similarity. separability, and the triangle inequality Psychological Revieu, 1982, 89, 123-154

Tversky. A and Kahneman. D. Causal schemas in judgments under uncertainty in M. Fishbein (Eds.). Progress in social psychology. Hillsdale. NJ Erlbaum 1980

VanLehn. K and Brown. J S Planning Nets A representation for formalizing anaiogies and semantic models of procedural skills In Snow, $R$. E. Federico, $P$ and Montague, W. E (Eds), Aptztude, Learning and Instruction. bolume 2 Hillsdale. NJ Erlbaum, 1980

Winston. $P H$ Learning new principles from precedents and exercises artificial Intellzgence, 1982, 19,321-350 


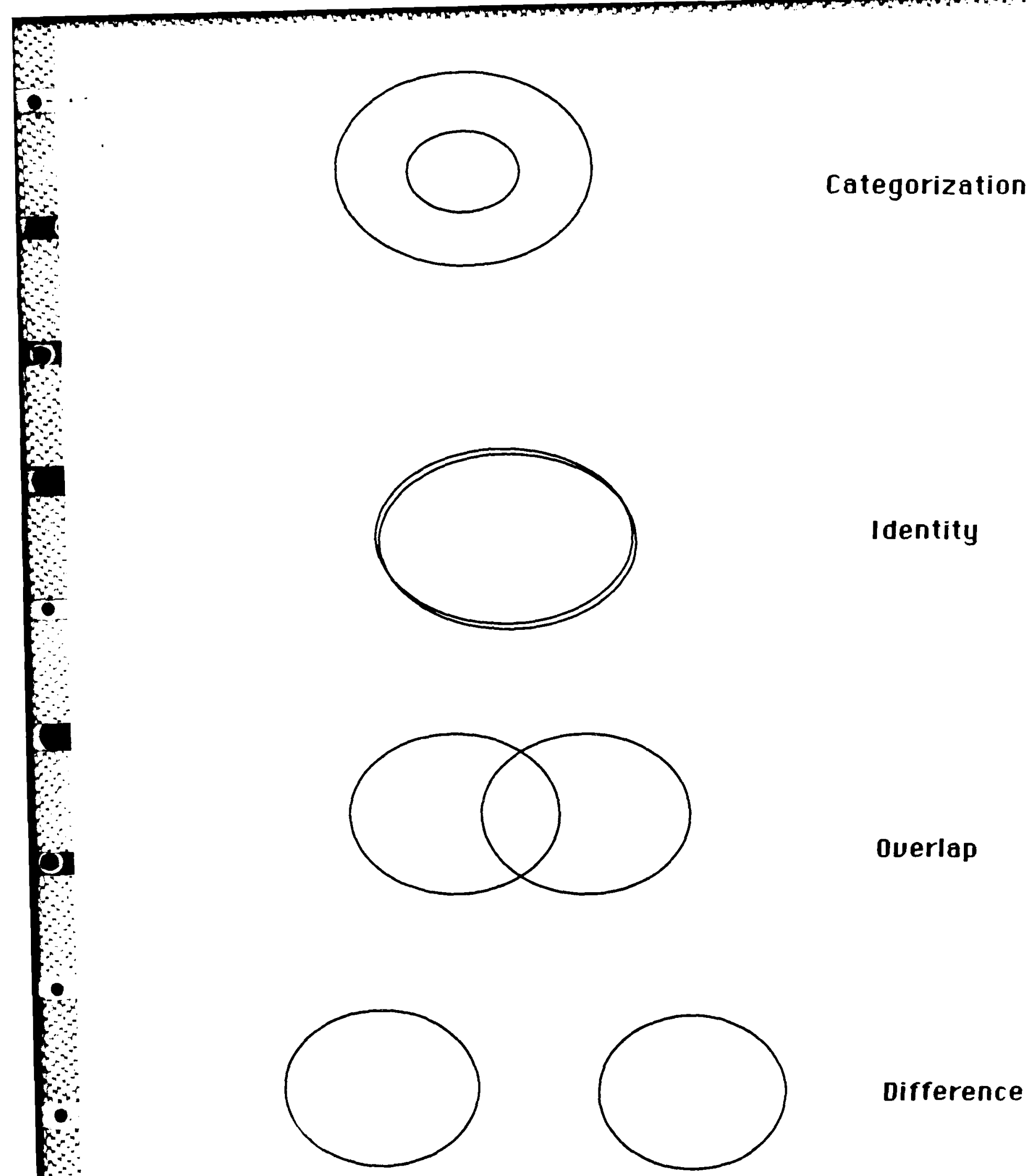

Figure 1 Four relations in comparing concepts. 

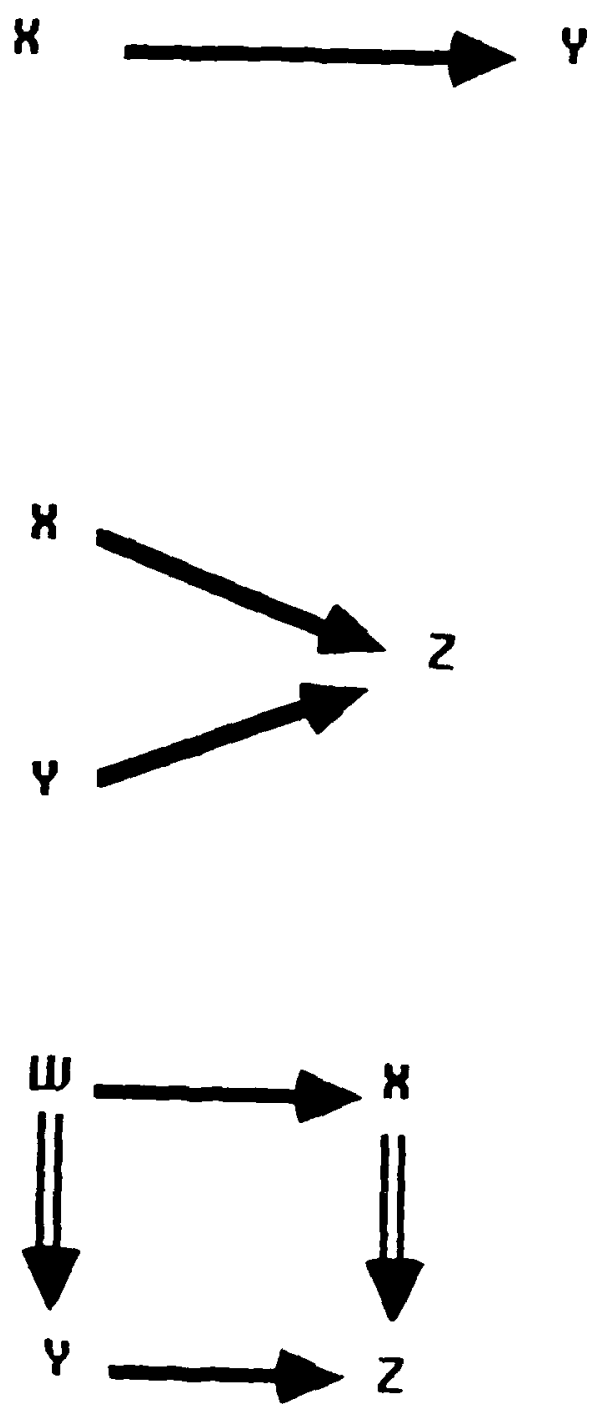

Two-element comparison

Three-element comparison

\section{Four-element comparison}

Figure 2 The structure of different comparisons of concepts. 